\title{
Pengembangan sensor seismik berbasis MEMS accelerometer
}

\author{
Amalia C. Nur'aidha ${ }^{* 1}$, Didik R. Santoso ${ }^{2}$, Sukir Maryanto ${ }^{2}$ \\ ${ }^{1}$ Fakultas Sains dan Teknologi, Universitas PGRI Yogyakarta \\ ${ }^{2}$ FMIPA,Universitas Brawijaya \\ Jl. IKIP PGRI I No.117, Kab. Bantul - D.I Yogyakarta \\ Jl. Veteran, Malang - Jawa Timur \\ *email: amalia@upy.ac.id
}

\begin{abstract}
Abstrak - Sensor seismik merupakan komponen utama dalam bidang seismologi. Salah satu sensor seismik yang sering digunakan geofon, namun geofon memiliki kekurangan dalam mendeteksi getaran frekuensi rendah di bawah $10 \mathrm{~Hz}$. Dengan adanya kekurangan tersebut menjadi salah satu peluang bagi sensor MEMS yang memiliki rentang frekuensi lebih lebar dibandingkan dengan geofon.Pada penelitian ini sensor MEMS terkonfigurasi dengan pengkondisi sinyal yang telah dilengkapi dengan rangkaian integrator. Fungsi dari rangkaian integrator ini untuk mengubah MEMS Percepatan menjadi MEMS Kecepatan. Sehingga MEMS mampu mendeteksi kecepatan gerakan tanah menyerupai geofon. Hasil respon sinyal MEMS menunjukkan bahwa MEMS Kecepatan mampu mendeteksi getaran frekuensi $0.01 \mathrm{~Hz}$ hingga $100 \mathrm{~Hz}$. Berdasarkan hasil respon frekuensi menunjukkan bahwa MEMS mampu digunakan sebagai sensor seismik.
\end{abstract}

Kata kunci: Sensor Seismik, MEMS, Accelerometer

Abstract - All Seismic sensors are the main component in seismology. One of the seismic sensors that are geophones, but geophones have a weakness below 10Hz. That is a MEMS sensor opportunity because MEMS has a wide frequency range than geophones. In this study, the MEMS sensor configured with a signal conditioning system that has equipped with an integrator. The function of this integrator is to convert MEMS Acceleration to MEMS Velocity. So MEMS can detect the velocity ground motion like a geophone. The result $M E M S$ frequency signal response shows MEMS that supported with a frequency of $0.01 \mathrm{~Hz}$ to $100 \mathrm{~Hz}$. Based on the results of the frequency response shows that MEMS has the capability as a seismic sensor.

Key words: Seismic Sensor, MEMS, Accelerometer

\section{PENDAHULUAN}

Sensor getaran untuk deteksi seismik (sensor seismik) merupakan komponen utama dalam bidang seismologi, seperti pemantauan bencana alam dan inspeksi geofisika untuk sumber daya mineral [1][2][3]. Sensor tersebut mampu mengirimkan getaran tanah yang muncul ke dalam sinyal listrik [4][5]. Beberapa sensor seismik telah dikembangkan dalam berbagai prinsip yang dapat diklasifikasikan menjadi accelerometer piezoelektrik, mikro piezoresistive, elektromagnetik, mikro kapasitansi, sensor arus eddy, serat optik, dan pendulum [6][7][5].

Salah satu sensor seismik yang sering digunakan saat ini adalah geofon dengan mengaplikasikan prinsip elektromagnetik. Sensor ini telah menjadi sensor standar yang digunakan dalam pencitraan seismik. Sensor tersebut merupakan sensor pasif yang terdiri dari kumparan yang dipasangkan dengan pegas lunak yang bergerak relatif terhadap magnet tetap [8]. Geofon bekerja mengukur kecepatan dengan menghasilkan tegangan pada kumparan yang bergerak bebas dalam medan magnet [9].

Geofon memiliki respon sekitar $10 \mathrm{~Hz}$, apabila terdapat frekuensi di bawah $10 \mathrm{~Hz}$ maka respon dari geofon akan berkurang $12 \mathrm{~dB}$ per decade [9][10]. Geofon tipe SM-24 memiliki bentuk yang sangat sederhana dengan ukuran sensor $\sim 3 \mathrm{~cm}$ dan berat $\pm 75 \mathrm{~g}$ [11]. Tipe sensor tersebut memiliki ground noise yang relatif rendah namun sensor tersebut memiliki kekurangan yaitu, rentang frekuensi linearnya terbatas di atas frekuensi alaminya, biasanya 4$12 \mathrm{~Hz}$ [12].

Saat ini pada bidang seismologi sangat dibutuhkan sensor yang memiliki biaya yang rendah serta dilengkapi kemampuan frekuensi yang lebar [1]. Dari berbagai sensor seismik yang telah dikembangkan, pendekatan accelerometer menghasilkan hasil yang cukup baik ketika dilakukan pengukuran getaran pada frekuensi yang rendah pada bidang seismologi [6]. Salah satu sensor yang dapat dikembangkan 
dengan pendekatan accelerometer adalah sensor MEMS.

Saat ini telah terdapat trend baru dalam bidang industri untuk menggantikan geofon dengan MEMS [8]. MEMS tersebut memiliki kelebihan yang dapat menghasilkan broadband (0 hingga $800 \mathrm{~Hz}$ ), nilai noise yang lebih rendah (kurang lebih -10dB) [13] serta konsumsi daya yang rendah [14][15]. Jika dibandingkan dengan geofon sensor MEMS memiliki sensitivitas lebih tinggi, baik untuk frekuensi rendah maupun frekuensi tinggi [13]. Bandwidth MEMS ini lebih lebar jika dibandingkan dengan geofon yaitu, 10-100Hz. MEMS bekerja di bawah frekuensi resonansi percepatan, sedangkan geofon bekerja di atas frekuensi resonansi kecepatan. Cakupan frekuensi MEMS tersebut mampu merekam getaran pada frekuensi rendah menjadi sangat penting, khususnya untuk pemantauan seismik [16]. Berdasarkan hal tersebut maka pada penelitian ini akan dilakukan pengembangan sensor seismik menggunakan MEMS percepatan.

\section{METODE PENELITIAN}

MEMS percepatan termasuk dalam klasifikasi sensor kapasitif, salah satu tipe sensor ini adalah MMA7361L. MMA7361L berbentuk chip IC yang dibuat oleh Freescale Semikoduktor (Gambar 1). Sensor tersebut dilengkapi beberapa kelebihan yaitu, energi yang digunakan sangat rendah, memiliki 2 sensitivitas (1.5g dan $6 \mathrm{~g}$ ) yang dapat di atur sesuai dengan kebutuhan dengan kamampuan maksimal sensitivitas $800 \mathrm{mV} / \mathrm{g} @ 1.5 \mathrm{~g}$ serta memiliki 3 komponen penginderaan (x,y, dan $\mathrm{z})$ [13].

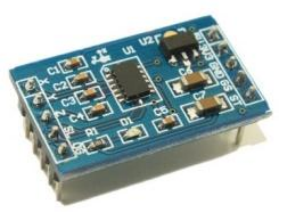

Gambar 1. Sensor MEMS Percepatan MMA7361L

Sensor MEMS tidak dapat digunakan secara langsung sebagai sensor seismik. Sensor tersebut memerlukan rangkaian tambahan (Sistem Akusisi Data). Blok diagram (Gambar 2) merupakan desain sistem akuisisi data untuk melengkapi sensor MEMS supaya dapat digunakan sebagai sensor seismik. Sensor MEMS akan menangkap sinyal yang berasal dari sumber getar (Gerakan tanah). Keluaran dari sensor MEMS (pada pin output)akan diolah di dalam pengkondisi sinyal dan pemroses sinyal, sehingga dapat di tampilkan pada media penampil.

Tahap awal yang dilakukan yaitu melakukan simulasi terlebih dahulu menggunakan software circuit maker untuk mengetahui respon frekuensi dari sensor geofon sebagai sensor yang telah sering digunakan dalam bidang seismologi (Gambar 3). Berdasarkan gambar tersebut dapat dilihat bahwa geofon memiliki respon frekuensi di atas $10 \mathrm{~Hz}$ dan tidak mampu merespon frekuensi di bawah $10 \mathrm{~Hz}$. Ketidakmampuan geofon ini dikarenakan sistem kerja geofon adalah meloloskan frekuensi tinggi dengan menerapkan High Pass untuk mengurangi noise yang ada disekitar sensor. Sehingga apabila akan melakukan perluasan respon ke frekuensi yang lebih rendah tidak dapat dilakukan. Dengan adanya kekurangan tersebut menjadi salah satu peluang bagi sensor MEMS yang memiliki rentang frekuensi yang lebih lebar. Gambar 4 menampilkan respon frekuensi dari sensor MEMS. Berdasarkan gambar tersebut, tampak respon frekuensi sensor MEMS mulai dari $0.01 \mathrm{~Hz}$ hingga $100 \mathrm{~Hz}$.

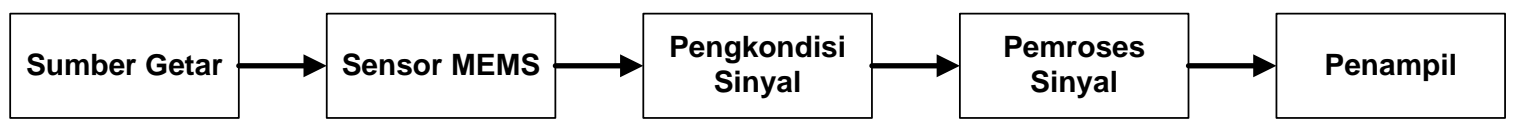

Gambar 2. Diagram Blok Desain Akuisisi Data 


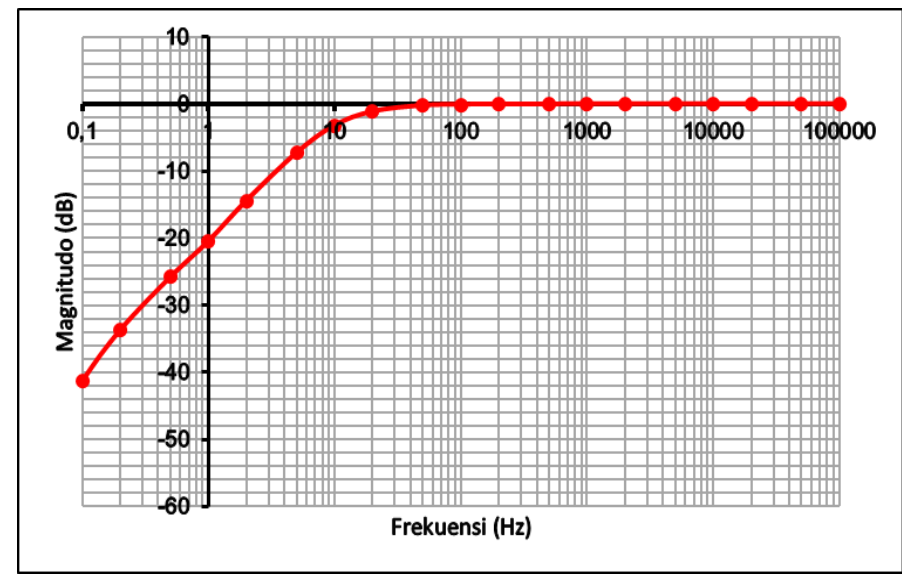

Gambar 3. Respon Frekuensi Geofon

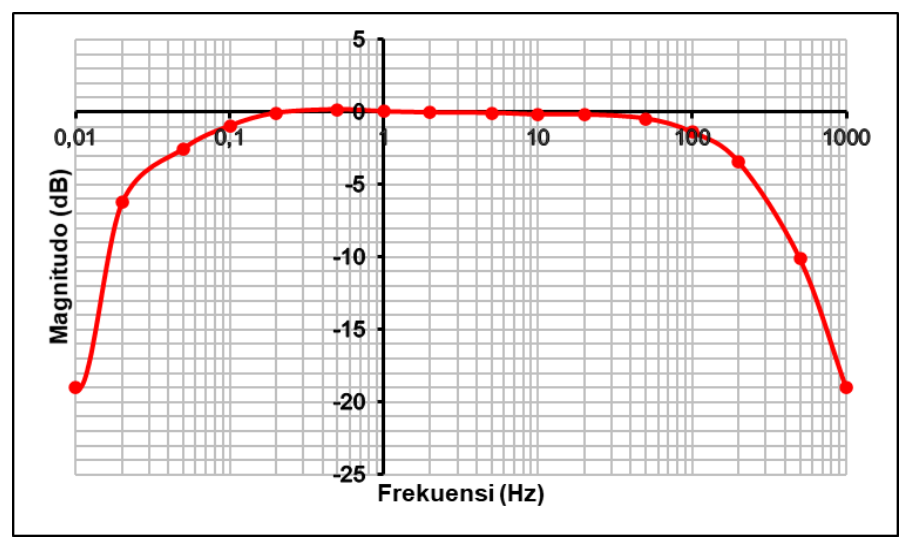

Gambar 4. Respon Frekuensi MEMS MMA7361L

Sensor MEMS pada dasarnya bekerja mendeteksi percepatan dari gerakan tanah. Pada penelitian ini keluaran dari sensor MEMS yang berupa percepatan akan di ubah menjadi kecepatan di dalam proses pengkondisi sinyal. Proses perubahan ini dilakukan supaya sensor MEMS serupa dengan geofon yang berkerja mendeteksi kecepatan gerakan tanah. Rangkaian pengkondisi sinyal ini dilengkapi dengan rangkaian integrator yang dilengkapi kombinasi nilai $\mathrm{R}_{1}=15 \mathrm{k}, \mathrm{R}_{2}=330 \mathrm{k}$, dan $\mathrm{C}=1 \mu($ Gambar $5)$ yang berfungsi mengubah sinyal percepatan MEMS menjadi sinyal kecepatan.

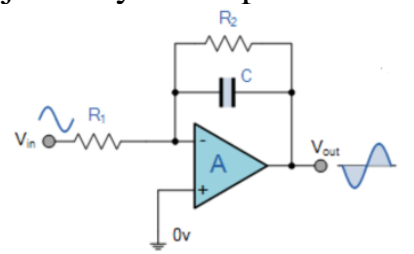

Gambar 5. Rangkaian Integrator
Sebelum menerapkan sensor MEMS beserta pengkondisi sinyalnya dilakukan terlebih dahulu tahap pengujian menggunakan simulasi. Hasil simulasi keluaran pengkondisi sinyal yang dilengkapi dengan integrator ditunjukkan oleh gambar 6. Berdasarkan hasil simulasi yang dilakukan oleh software tampak pada gambar, sinyal masukan yang berupa sinyal percepatan yang ditandai dengan sinyal sinus (garis hijau) terdapat perubahan pada sinyal keluaran berupa kecepatan yang ditandai dengan adanya perubahan sinyal menjadi cosinus (garis biru).

Berdasarkan dari hasil simulasi yang telah dilakukan, maka pada penelitian ini akan dilakukan pengembangan sensor MEMS sebagai sensor seismik. 


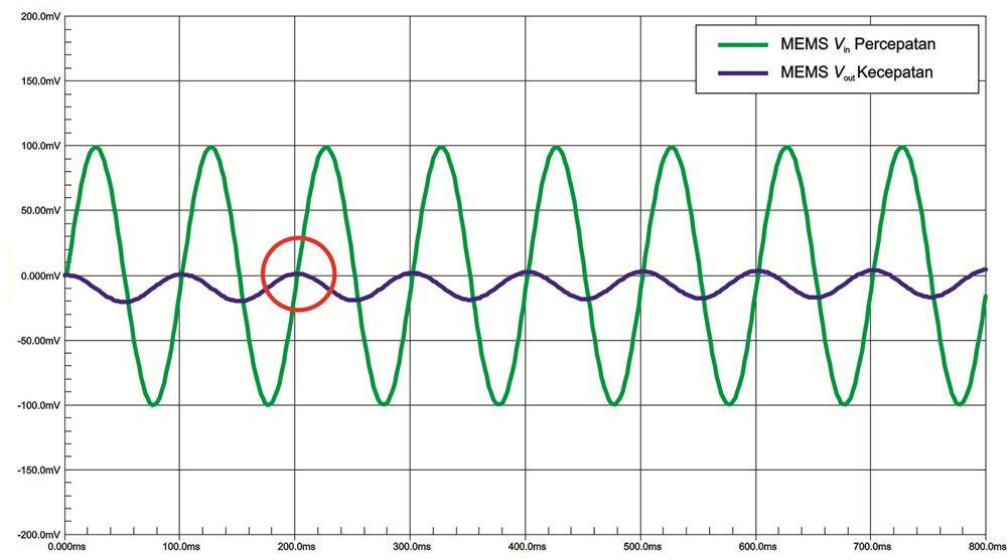

Gambar 6. Hasil Simulasi Masukan dan Keluaran Sinyal pada Pengkondisi Sinyal

\section{HASIL DAN PEMBAHASAN}

Implementasi dari metode yang telah dipaparkan sebelumnya yaitu melakukan pengujian dalam skala laboratoium dengan menggunakan cantilevar beam (Gambar 7) untuk melihat respon frekuensi dari MEMS serta membandingkan dengan geofon SM-24.

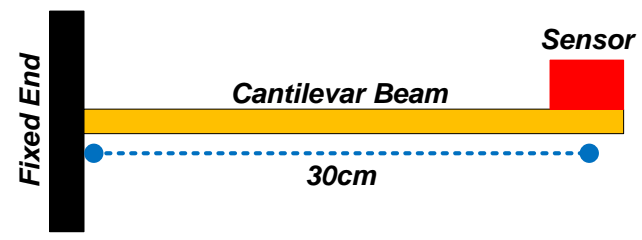

Gambar 7. Pengujian Sensor menggunakan Cantilevar Beam

Tahap pertama pengujian yaitu, menguji sensor MEMS tanpa pengkondisi sinyal tambahan dengan sensor MEMS yang telah dilengkapi dengan pengkondisi sinyal. Gambar 8 menyajikan konfigurasi tahap pertama untuk membandingkan sensor MEMS tanpa pengkondisi sinyal tambahan (MEMS Percepatan) dengan sensor MEMS yang telah dilengkapi dengan pengkondisi sinyal (MEMS Kecepatan).

Hasil pengujian tahap pertama disajikan pada gambar 9. Tampak hasil pengujian kedua sensor MEMS masih memiliki respon frekuensi yang sama, namun terdapat perbedaan. Dapat dilihat untuk sensor MEMS Percepatan memiliki noise yang cukup besar sedangkan untuk MEMS Kecepatan noise yang terdeteksi telah berkurang. Hal ini disebabkan karena pada pengkondisi sinyal telah dilengkapi fungsi untuk mengurangi noise disekitar sensor. Setelah melakukan pengujian tahap pertama, dilakukan pengujian tahap selanjutnya yaitu melakukan proses uji untuk MEMS Kecepatan dengan Geofon SM-24. Konfigurasi pengujian ini disajikan pada gambar 10.

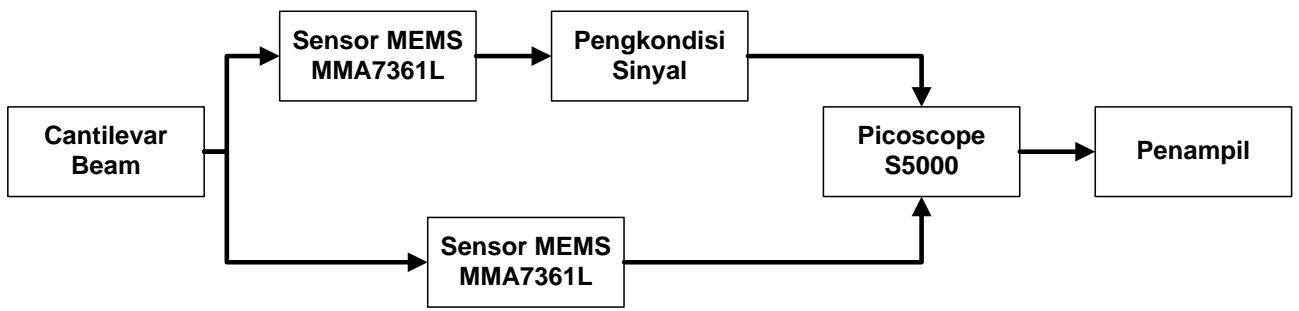

Gambar 8. Konfigurasi Pengujian MEMS Accelerometer dengan MEMS Velocity 


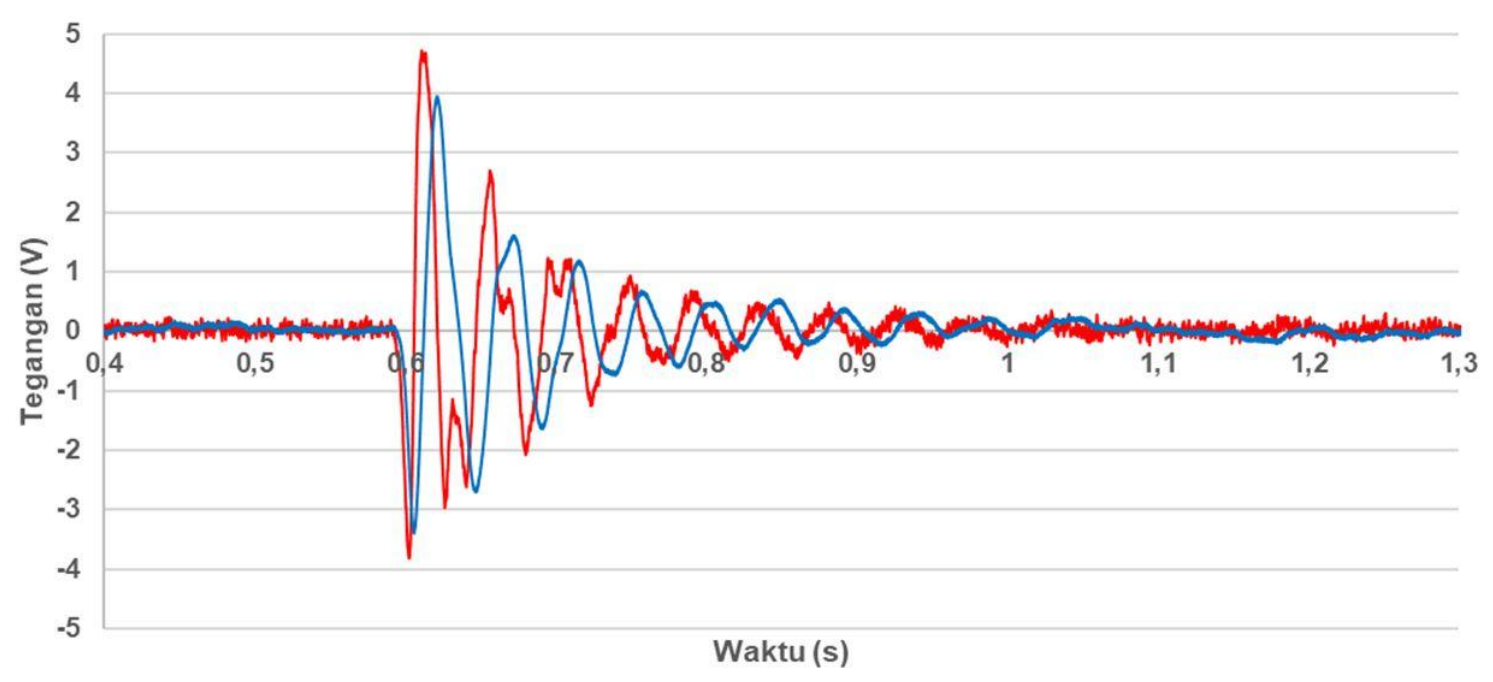

Gambar 9. Hasil Pengujian MEMS Accelerometer (Merah) dengan MEMS Velocity (Biru)

Hasil respon sinyal MEMS kecepatan dengan Geofon SM-24 tampak pada gambar 11. Garis berwarna biru merupakan sinyal yang dihasilkan oleh geofon dan garis berwarna merah adalah sinyal yang dihasilkan oleh MEMS. Pengujian respon sinyal dilakukan dengan memberikan getaran frekuensi tinggi dan frekuensi rendah. Gambar 11a merupakan hasil respon sinyal untuk frekuensi tinggi, dapat dilihat pada frekuensi tinggi baik MEMS maupun Geofon memiliki nilai amplitudo yang sama. Hal ini dapat dikatakan bahwa pada getaran frekuensi tinggi MEMS dapat mendeteksi getaran dengan baik dan sebanding dengan geofon. Sedangkan untuk hasil respon sinyal getaran frekuensi rendah disajikan pada gambar 11b, dapat dilihat pada gambar bahwa MEMS memiliki nilai amplitudo yang lebih besar jika dibandingkan dengan geofon. Hal ini disebabkan karena geofon tidak mampu mendeteksi frekuensi rendah di bawah $10 \mathrm{~Hz}$, sedangkan MEMS mampu mendeteksi getaran frekuensi rendah mulai dari $0.01 \mathrm{~Hz}$.

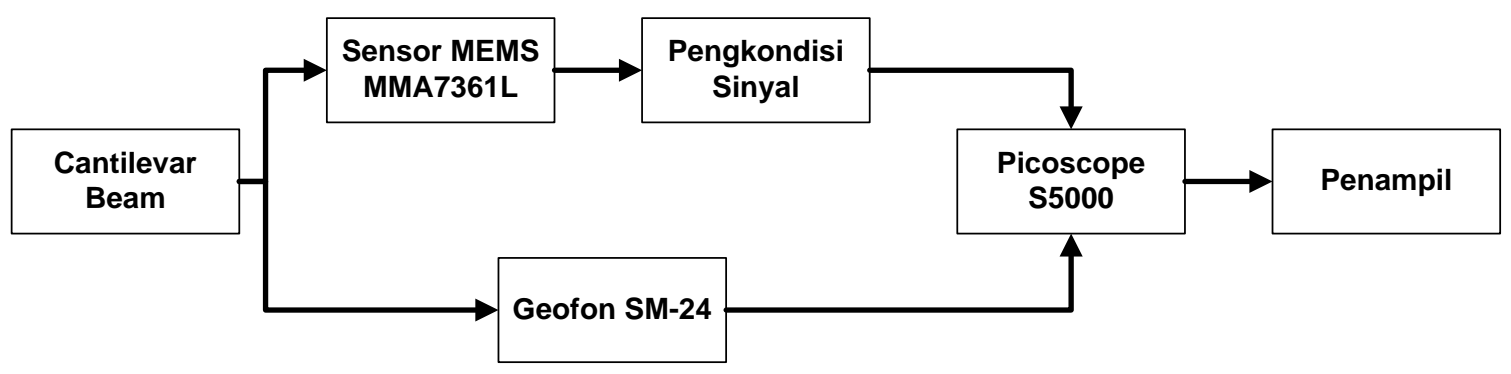

Gambar 10. Konfigurasi Pengujian MEMS dengan Geofon 


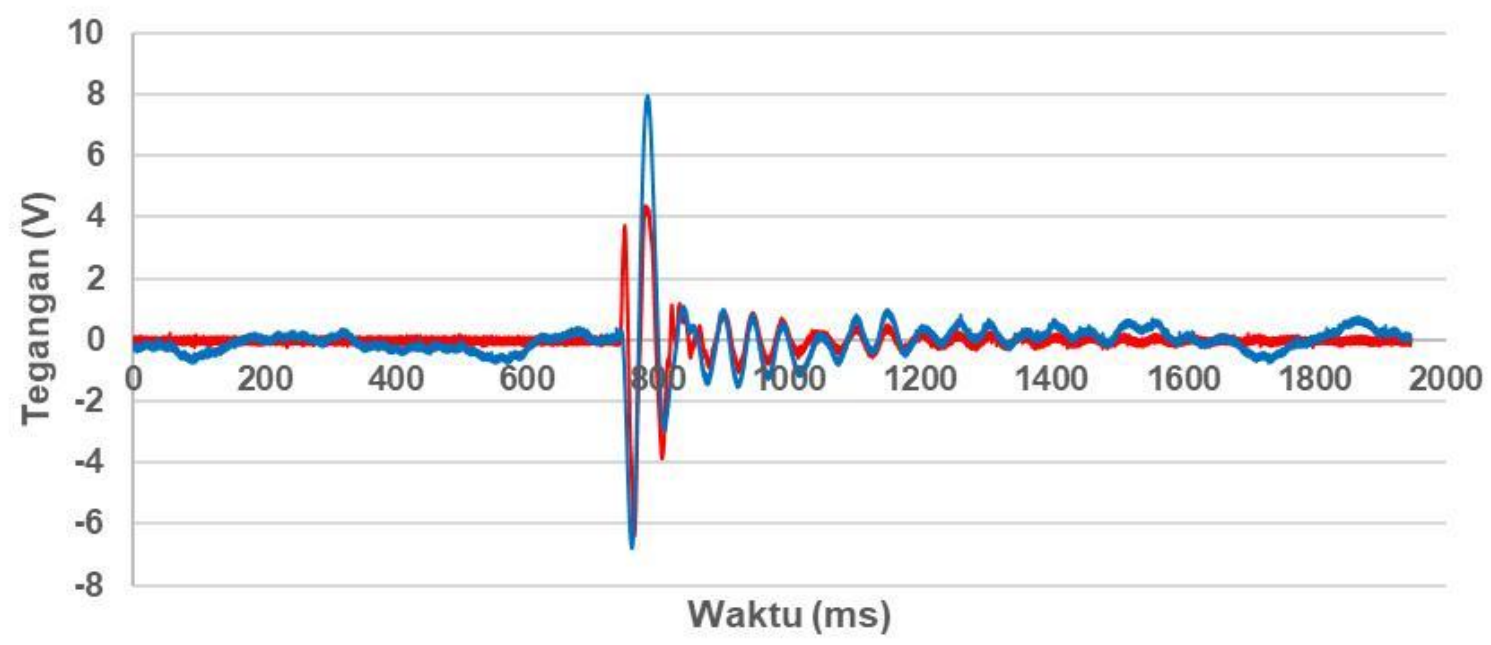

(a)

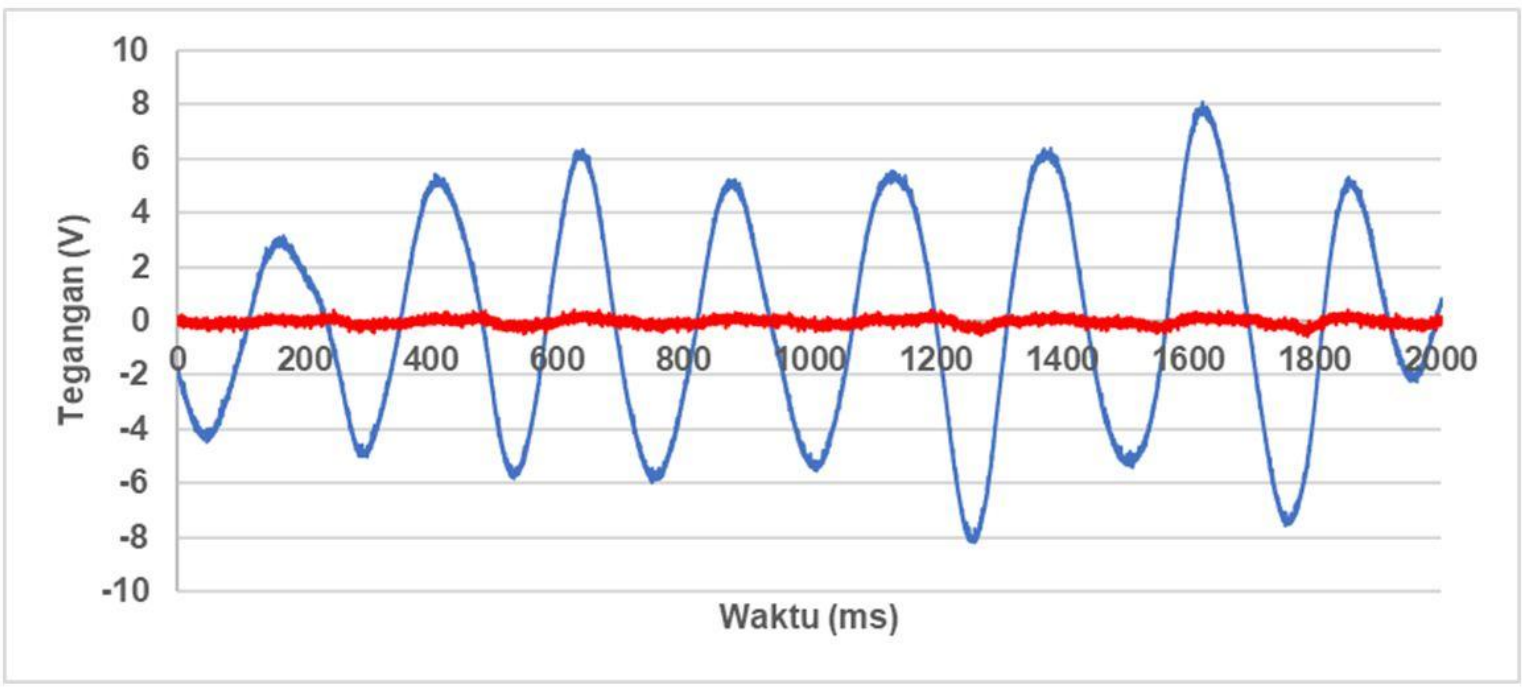

(b)

Gambar 11. (a) Hasil Pengujian Frekuensi Tinggi MEMS (Biru) dengan Geofon (Merah), (b)Hasil Pengujian Frekuensi Rendah MEMS (Biru) dengan Geofon (Merah)

\section{KESIMPULAN}

Penelitian ini mengembangkan sensor MEMS sebagai sensor seismik. Sensor yang digunakan adalah sensor MEMS MMA7361L dilengkapi dengan pengkondisi sinyal. Dimana pengkondisi sinyal ini dilengkapi dengan rangkaian integrator yang berfungsi merubah percepatan menjadi kecepatan. Sehingga sensor MEMS mampu mendeteksi kecepatan gerakan tanah. Sensor tersebut mampu mendeteksi getaran dengan rentang frekuensi $0.01 \mathrm{~Hz}$ hingga $100 \mathrm{~Hz}$. Dengan demikian sensor MEMS dapat dikatakan telah mampu digunakan sebagai sesnor seismik yang mampu mendeteksi getaran frekuensi rendah hingga frekuensi tinggi

\section{UCAPAN TERIMA KASIH}

Penulis mengucapkan terimakasih kepada semua anggota Laboratorium Riset Measurement, Circuit and System, Universitas Brawijaya dan rekan-rekan Tim yang telah membantu mengimplementasikan penelitian ini.

\section{DAFTAR PUSTAKA}

[1] T. Deng, D. Y. Chen, J. B. Wang, J. Chen, W. T. He, and Y. J. Fan, A MEMS based electrochemical seismic sensor, 2013 Transducers Eurosensors XXVII 17th Int. Conf. Solid-State Sensors, Actuators 
Microsystems, TRANSDUCERS EUROSENSORS 2013, June (2013) 920923,doi: 0.1109/Transducers.2013.6626918

[2] T. Deng, D. Chen, J. Wang, J. Chen, and W. He, A MEMS Based Electrochemical Vibration Sensor for Seismic Motion Monitoring, J. Microelectromechanical Syst., 23(1) (2014) 92-99.

[3] T. Deng, D. Chen, J. Chen, Z. Sun, G. Li, and J. Wang, "Microelectromechanical Systems-Based Electrochemical Seismic Sensors with Insulating Spacers Integrated Electrodes for Planetary Exploration", IEEE Sens. J., 16(3) (2016) 650-653, doi: 10.1109/JSEN.2015.2491783.

[4] G. Li et al., "A MEMS based seismic sensor using the electrochemical approach," Procedia Eng., 47 (2012) 362365, doi: 10.1016/j.proeng.2012.09.158.

[5] D. Chen et al., "Sensors and Actuators A : Physical A micro electrochemical seismic sensor based on MEMS technologies," Sensors Actuators A. Phys., 202 (2013) 8589, doi: 10.1016/j.sna.2012.12.041.

[6] C. T. Chiang, "Design of a CMOS MEMS Accelerometer Used in IoT Devices for Seismic Detection," IEEE J. Emerg. Sel. Top. Circuits Syst., 8(3) (2018) 566-577, doi: 10.1109/JETCAS.2018.2825604.

[7] M. Pandit, C. Zhao, G. Sobreviela, X. Zou, and A. A. Seshia, Seismic Recording Using A Mode Localized Mems Accelerometer, Nanoscience Center, Department of Engineering, University of Cambridge, Cambridge, UK MOE Key Laboratory of Fundamental Physical Quantities Measurement \& Hubei Key Laboratory of Gravitation a," 2019 20th Int. Conf. SolidState Sensors, Actuators Microsystems Eurosensors XXXIII (TRANSDUCERS EUROSENSORS XXXIII), June (2019) 2150-2153,.

[8] D. J. Milligan, B. D. Hom, and R. G. Walmsley, "An Ultra-Low N Noise MEMS Accelerom meter for Seismic Imaging," IEEE Sens. J., (2011) 8-11, doi: 10.1109/ICSENS.2011.6127185.
[9] N. Hakimitoroghi, R. Raut, M. Mirshafiei, and A. Bagchi, "Compensation techniques for geophone response used as vibration sensor in seismic applications," Proc. Int. Conf. Sens. Technol. ICST, 2017 (2018) 15, doi: 10.1109/ICSensT.2017.8304423.

[10] R. G. Walmsley and P. G. Hartwell, "Hewlett packard's seismic grade mems accelerometer," IEEE Sens. J., (2011) 585588 ,

[11] J. Laine and D. Mougenot, "Benefits Of MEMS Based Seismic Accelerometers For Oil Exploration," in Transducers \& Eurosensors, (2007) 1473-1477.

[12] R. Brincker, B. Bolton, A. Brandt, B. Allé, and D.-O. M, "Calibration and Processing of Geophone Signals for Structural Vibration Measurements," in Experimental Mechanics, (2010) 1-5.

[13] J. Lainé and D. Mougenot, "A highsensitivity MEMS-based accelerometer," Lead. EDGE, November (2014) 12341242.

[14] R. Levy, G. Papin, O. Le Traon, D. Janiaud, and J. Guerard, A high resolution vibrating beam accelerometer working in nonlinear region for seismic ground sensor application, DTIP 2014 - Symp. Des. Test, Integr. Packag. MEMS/MOEMS, April (2014) 4-6, doi: 10.1109/DTIP.2014.7056683.

[15] F. A. Levinzon, "Ultra-low-noise seismic piezoelectric accelerometer with integral FET amplifier," IEEE Sens. J., 12(6) (2012) 2262-2268, doi: 10.1109/JSEN.2012.2186564.

[16] T. Aizawa, T. Kimura, T. Matsuoka, T. Takeda, and Y. Asano, "Application of MEMS accelerometer to geophysics," Int. J. Mech., 4(2) (2008) 1-4. 